\title{
COMPARISON OF ETOMIDATE AND THIOPENTONE SODIUM AS ANAESTHETIC AGENTS FOR MODIFIED ELECTROCONVULSIVE THERAPY
}

\author{
Balaji Donthu' ${ }^{1}$ Kavya $^{2}$, Vara Subramanyam ${ }^{3}$
}

${ }^{1}$ Assistant Professor, Department of Anaesthesiology, Rajiv Gandhi Institute of Medical Sciences, Kadapa.

${ }^{2}$ Assistant Professor, Department of Anaesthesiology, Rajiv Gandhi Institute of Medical Sciences, Kadapa.

${ }^{3}$ Postgraduate Student, Department of Anaesthesiology, Rajiv Gandhi Institute of Medical Sciences, Kadapa.

ABSTRACT

\section{BACKGROUND}

Electroconvulsive Therapy (ECT) is considered to be one of the most commonly used procedure in psychiatry practice.

This prospective study was designed to compare the effects of etomidate and sodium thiopentone used in ECT on seizure threshold and duration, haemodynamics, recovery from ECT and immediate side effects.

\section{MATERIALS AND METHODS}

100 adult patients with major depressive disorder who were referred for ECT were included in the study. The patients were randomly allocated into one of the two groups. Group E received intravenous etomidate $(0.2 \mathrm{mg} / \mathrm{kg})$. Group T received intravenous sodium thiopental $(2.5 \%, 3 \mathrm{mg} / \mathrm{kg})$. All the patients received bilateral ECT. The outcome measures included seizure threshold and duration, haemodynamics and recovery from ECT.

\section{RESULTS}

The mean seizure duration in etomidate group was $38.9 \pm 4.3$ seconds vs. $33.5 \pm 2.7$ seconds in the thiopentone group (P $<0.01$ ). Etomidate has more haemodynamic stability compared to sodium thiopentone. ( $\mathrm{P}<0.05$ up to 5 mins.). Recovery from anaesthesia was faster in etomidate group than in thiopentone group ( $7.82 \pm 1.8$ vs $8.96 \pm 2.5$ minutes).

\section{CONCLUSION}

We conclude that etomidate when compared to thiopentone sodium is a safe anaesthetic agent for electroconvulsive therapy with minimal side effects.

\section{KEYWORDS}

ECT, Etomidate, Haemodynamic Stability, Sodium Thiopentone, Seizure Duration.

HOW TO CITE THIS ARTICLE: Donthu B, Kavya, Subramanyam V. Comparison of etomidate and thiopentone sodium as anaesthetic agents for modified electroconvulsive therapy. J. Evolution Med. Dent. Sci. 2017;6(7):532-535, DOI: $10.14260 /$ Jemds/2017/113

\section{BACKGROUND}

Electroconvulsive Therapy (ECT) is a commonly used treatment procedure for many psychiatric disorders such as major depressive disorder, bipolar mood disorder and schizophrenia. The essential features of anaesthesia for ECT include rapid loss of consciousness, effective attenuation of the haemodynamic response to the electrical stimulus, avoidance of gross movements, minimal interference with seizure activity and prompt recovery of spontaneous ventilation and consciousness.[1] Use of general anaesthetic techniques with a rapid onset and recovery is essential to facilitate fast tracking. Number of drugs such as sodium thiopental, etomidate, methohexital, propofol, ketamine, alfentanil, remifentanil, lorazepam, midazolam and sevoflurane have already been used for induction of anaesthesia in ECT.[2]

Financial or Other, Competing Interest: None.

Submission 13-12-2016, Peer Review 04-01-2017,

Acceptance 16-01-2017, Published 23-01-2017.

Corresponding Author:

Dr. Balaji Donthu,

Flat No. 105,

Sri Krishna Sai Apartments,

Besides Bali Reddy Hospital,

Co-Operative Colony,

Kadapa-516001,

Andhra Pradesh.

E-mail:drvaasu@gmail.com

DOI: $10.14260 /$ jemds $/ 2017 / 113$
Thiopentone Sodium is a short-acting barbiturate that is commonly used for general anaesthesia for the treatment of ischaemic brain injury and for the treatment of neurosurgical situations such as high intracranial pressure. In higher doses, it can be used to treat refractory status epilepticus. Thiopentone produces a decrease in the cerebral metabolic rate, cerebral blood flow and intracranial pressure. Its effects on the cardiovascular system are a decrease in the mean arterial blood pressure and a decrease in cardiac output.[3] Significant side effects of thiopental are laryngeal spasm and respiratory depression.[4] Benign allergic skin reactions are common, but a serious allergic reaction is rare.

Etomidate is imidazole carboxylate derivative. It acts by activating the gamma aminobutyric acid inhibitory function. Etomidate has a rapid onset of action and rapidly induces hypnosis after intravenous administration. [5] It also produces rapid recovery from anaesthesia. Etomidate has minimal impacts on seizure duration. In addition, there is a trivial effect of etomidate on cardiopulmonary function. ${ }^{[6]}$ Some disadvantages with etomidate includes more expensive, the suppression of adrenal function and more injection pain.

This study was aimed to assess the comparative effects of thiopentone sodium and etomidate on recovery profile, haemodynamic stability and seizure duration. It was also done to study whether etomidate has a better recovery profile than thiopentone and if it is haemodynamically stable. 


\section{MATERIALS AND METHODS}

This is a prospective double-blind randomised clinical trial with a crossover design conducted on 100 ECT patient sessions. Patients who were between 20 and 60 years of age with a major depressive episode as part of a diagnosis of either major depressive disorder or bipolar disorder (International Classification of Diseases, 10th edition Code 296) were included in the study. Patients belonging to ASA physical status 3, 4 and 5; patients with history of cardiovascular and cerebrovascular disease, high intracranial pressure, respiratory tract diseases, glaucoma, high intraocular pressure, uncontrolled diabetes and hypertension, previous history of epilepsy, alcohol and drug abuse with history of sensitivity to anaesthetic agents, pregnancy, other psychiatric disorders and dementia were excluded.

The study protocol was approved by the Institutional Ethical Committee. Written Informed Consent was taken from each subject willing to enter the study. Pre-anaesthetic checkup and routine investigations like complete blood count, serum creatinine, electrocardiogram and chest x-ray were done. Patients were kept nil by mouth for 6 hours. Concurrent medications were continued as per the psychiatrist's recommendation. Monoamine Oxidase (MAO) inhibitors and lithium were discontinued prior to anaesthesia.

The patients were randomly allocated into two groups of 50 each according to intravenous anaesthetic drugs administered for induction of general anaesthesia. There was a 1:1 ratio for randomisation. The patients and the rater were blinded to the groups. Group E received intravenous etomidate $(0.2 \mathrm{mg} / \mathrm{kg})$. Group T received intravenous sodium thiopental (2.5\%, $3 \mathrm{mg} / \mathrm{kg})$.

After shifting the patient into operation theatre, IV line was secured with a large bore cannula. All non-invasive monitors like Non-Invasive Blood Pressure (NIBP), pulse rate, oxygen saturation and Electrocardiogram (ECG) were applied to all patients and their baseline vital signs were measured. All patients received glycopyrrolate $0.1 \mathrm{mg} / \mathrm{kg}$ IV. In Group E, induction was achieved with injection etomidate $0.2 \mathrm{mg} / \mathrm{kg}$ Intravenous (IV), whereas in group T induction was achieved with thiopentone $3 \mathrm{mg} / \mathrm{kg}$ IV. Succinylcholine $0.4 \mathrm{mg} / \mathrm{kg}$ IV was given for neuromuscular blockade to reduce the muscle contractions associated with ECT-induced seizure activity. Ventilation is assisted with help of a face mask using a standard Mapleson D breathing system. ECT was administered twice a week using a brief-pulse, square-wave, constant-current ECT device $(120 \mathrm{mC}, 70 \mathrm{~Hz} / 0.1 \mathrm{sec})$. Bilateral ECT was given using the standard bifrontotemporal placement.

Outcome measures recorded included duration of seizure, amount of energy (in Joules) delivered and duration of recovery from the anaesthesia (Response to verbal command). Other data recorded included demographic profile such as age, sex, weight, underlying disease, duration of hospitalisation, duration of disorder and number of ECT. Mean blood pressure, heart rate and pulse oximetry were evaluated and recorded before and at the end of the procedure.

\section{Statistical Analysis}

Data were expressed as mean \pm standard deviation for quantitative variables, number and percentage for categorical variables chi square $(\chi 2)$ test was used to compare in between groups. $\mathrm{P}<0.05$ was considered statistically significant.

\section{RESULTS}

The demographic profile of both groups are displayed in Table 1. The mean age of patients in both groups were statistically similar. There is no statistically significant differences in age, sex, pre-treatment severity of depression symptoms, weight or ASA status. In our study, the maximum number of patients presented with the diagnosis of severe depression (28\%) and schizophrenia (22\%) (Figure 1).

\begin{tabular}{|c|c|c|}
\hline Variable & Group E (n = 50) & Group T (n = 50) \\
\hline Age (years) & $31.16 \pm 8.24$ & $32.15 \pm 9.47$ \\
\hline Sex M:F & $28: 22$ & $30: 20$ \\
\hline Weight (kgs) & $74.26 \pm 16.42$ & $75.28 \pm 13.21$ \\
\hline ASA I:II & $23: 27$ & $21: 29$ \\
\hline BDI score at baseline & $40.2 \pm 5.4$ & $38.4 \pm 7.3$ \\
\hline \multicolumn{2}{|c|}{ Table 1. Demographic Data } \\
\hline
\end{tabular}

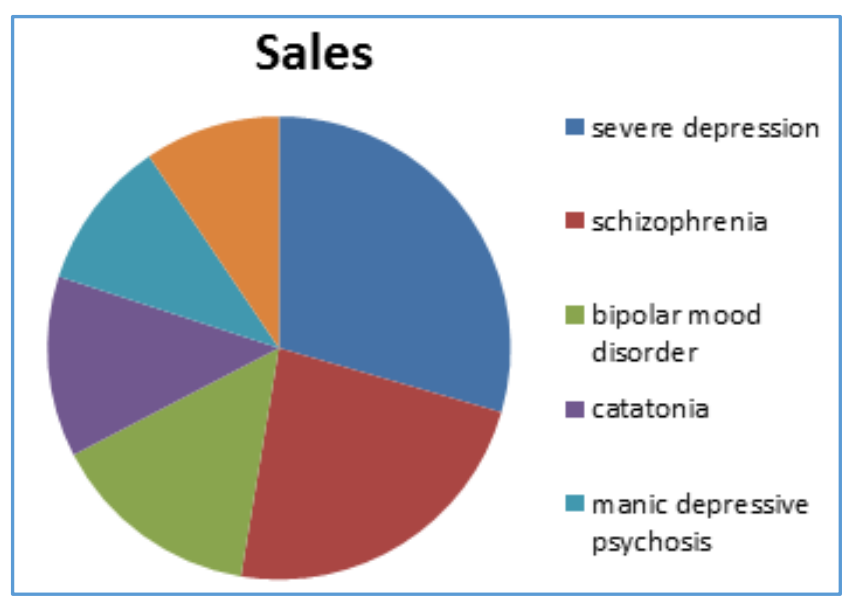

Figure 1. Type of Psychiatric Disorders

There was no significant difference in the Heart Rate (HR) between two groups at the times of pre-ECT (Table 2). There was maximum rise in the heart rate seen in the 1st minute after electroconvulsive therapy in both the groups, but the rise was comparatively more in the thiopentone group than in the etomidate group.

\begin{tabular}{|c|c|c|}
\hline Variable & Group E (n = 50) & Group T (n = 50) \\
\hline Pre-Anaes & $86.66 \pm 8.48$ & $88.31 \pm 8.64$ \\
\hline Induction & $89.13 \pm 9.16$ & $92.31 \pm 12.31$ \\
\hline Post ECT 1 min & $90.25 \pm 8.26$ & $121.54 \pm 14.36$ \\
\hline 2 mins & $89.28 \pm 8.44$ & $116.32 \pm 12.58$ \\
\hline 3 mins & $88.68 \pm 8.23$ & $110.48 \pm 15.69$ \\
\hline 5 mins & $88.23 \pm 8.28$ & $102.70 \pm 13.06$ \\
\hline 10 mins & $87.83 \pm 9.06$ & $94.52 \pm 14.15$ \\
\hline \multicolumn{3}{|c|}{ Table 2. Mean Heart Rate } \\
\hline
\end{tabular}

There was no significant difference in the pre-ECT Mean Arterial Pressure (MAP) between two groups. The change in mean arterial pressure was observed in a lesser number of patients in the etomidate group when compared to the 
thiopentone group (Table 3). The frequencies of adverse effects in both the groups are reported in Table 4.

\begin{tabular}{|c|c|c|}
\hline Variable & Group E (n = 50) & Group T (n = 50) \\
\hline Pre-Anaes & $92.74 \pm 9.22$ & $91.26 \pm 7.82$ \\
\hline Induction & $89.54 \pm 7.84$ & $88.57 \pm 8.06$ \\
\hline Post ECT 1 min & $90.27 \pm 8.36$ & $120.42 \pm 9.81$ \\
\hline 2 mins & $90.87 \pm 8.44$ & $115.47 \pm 8.71$ \\
\hline 3 mins & $89.76 \pm 8.02$ & $106.12 \pm 8.45$ \\
\hline 5 mins & $90.61 \pm 8.86$ & $101.26 \pm 8.40$ \\
\hline 10 mins & $91.24 \pm 8.12$ & $97.0 \pm 8.17$ \\
\hline \multicolumn{3}{|c|}{ Table 3. Mean Arterial Pressure } \\
\hline
\end{tabular}

\begin{tabular}{|c|c|c|}
\hline Variable & $\begin{array}{c}\text { Group E } \\
(n=50)\end{array}$ & $\begin{array}{c}\text { Group T } \\
(n=50)\end{array}$ \\
\hline Injection pain & $3(6 \%)$ & $3(6 \%)$ \\
\hline Allergy & $4(8 \%)$ & $3(6 \%)$ \\
\hline $\begin{array}{c}\begin{array}{c}\text { Postoperative nausea and } \\
\text { vomiting }\end{array} \\
\end{array}$ & $6(12 \%)$ & $4(8 \%)$ \\
\hline Myoclonus & $4(8 \%)$ & $0(0 \%)$ \\
\hline \multicolumn{3}{|c|}{ Table 4. Frequency of Adverse Effects } \\
\hline
\end{tabular}

Figure 2 indicates that the duration of seizure in the sodium thiopental group was lesser than that of the etomidate group. There was a statistically significant change in the recovery time between two groups. Etomidate had recovery time of around 7.82 mins and thiopentone around 8.96 mins (Figure 3). Etomidate has a better recovery time or very short duration of recovery compared to thiopentone sodium.

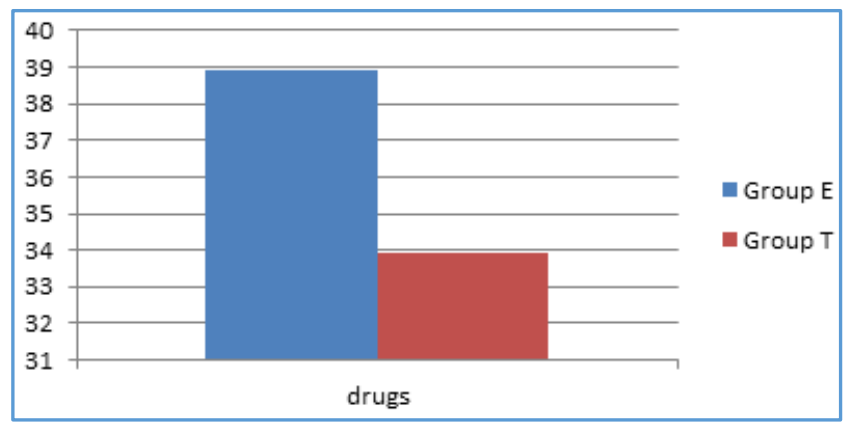

Figure 2. Comparison of Seizure Duration Between the Groups

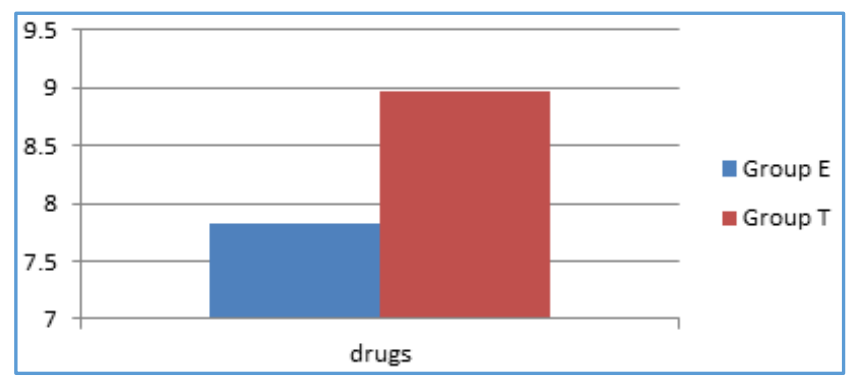

Figure 3. Mean Duration of Recovery (Minutes)

\section{DISCUSSION}

Presently, ECT has assumed an important role in the treatment of schizophrenic patients with affective disorders in the treatment of severe and medication-resistant depression and mania as well as suicidal drive, delusional symptoms, inanition, vegetative dysregulation and catatonic symptoms.[7] In acute phase of the illness, ECT is performed two to three times in a week for five to twelve treatments. In successful cases, an initial clinical improvement is usually evident after 3 to 5 treatments.[8] Maintenance therapy can be performed at progressively increasing intervals from once-aweek to once-a-month to prevent relapses. The characteristic features of an ideal anaesthetic agent used for electroconvulsive therapy includes rapid induction, shorter duration of action, minimal side effects, rapid recovery and no interference with electroconvulsive therapy efficiency.[9]

Many studies have investigated the role of anaesthetic medications on the outcome of ECT. One study compared the role of ketamine and thiopentone sodium. ${ }^{[10]}$ Another study compared ketamine and propofol.[11] Both studies indicate that there is a significant difference between different anaesthetic agents regarding the outcome of ECT on depressive symptoms.

In our study, the maximum number of patients presented with a diagnosis of severe depression (28\%) and schizophrenia (22\%). In a study conducted by Boey et al too in 1990, the most common conditions for which patients received electroconvulsive therapy were schizophrenia and severe depression.[12] The most important finding of this randomised double-blind study was that there was an association between group and post-intervention BDI score in patients with major depressive disorder. Etomidate was associated with a greater drop in BDI score than was sodium thiopental.

In our study, the duration of recovery was significantly different between the two groups. In a previous study by Rosa et al [on the three groups of patients who received ECT observed that recovery time was shorter with etomidate than that with sodium thiopentone].[13] The incidence of adverse effects was very similar except for myoclonus and postoperative nausea and vomiting.

Compared to propofol and sodium thiopentone, etomidate is used rarely as an anaesthetic agent for ECT. The American Psychiatric Association preferring etomidate for patients with resistance to seizure induction. In some patients with high seizure threshold, etomidate is the firstline medication and it can improve the therapeutic effects of ECT sessions. ${ }^{[14]}$ In the current study, seizure duration in ECT sessions in the etomidate group was longer than sodium thiopentone. Conca et al also observed similar findings with those in our study, in their study of 13 ECT patients.[15] Saffer and Berk concluded that etomidate was associated with a significantly longer seizure duration than sodium thiopentone.[16]

In our study, there was a statistically significant difference in the treatment course among the groups. Patients who were anaesthetised with thiopental received a lower treatment dose without an unwanted decrease in seizure duration; therefore, we conclude that thiopental might be the anaesthetic of choice when other medical considerations allow its use. Etomidate caused a decrease in pulse rate after ECT and stabilised the diastolic blood pressure; however, this finding was not expected in light of the current literature.[17]

In our study, there is no significant difference of baseline and pre-ECT haemodynamic parameters between the groups. Although, there was an increase in these parameters of both groups immediately after seizure, but the increase in the heart rate at the third and fifth minute after seizure was less in etomidate group compared to sodium thiopentone group. This implies that the haemodynamic conditions in the 
etomidate group varied insignificantly before and after the ECT, which is consistent with the findings of Hassan MA et al and Zahavi GS, who believed that etomidate provides a stable haemodynamic condition during ECT.[2]

Another interpretation to justify such findings is that the common haemodynamic changes after ECT include bradycardia immediately followed by tachycardia and eventually hypertension and since etomidate is haemodynamically more stable as compared to sodium thiopentone, it can effectively prevent the subsequent ECTinduced hypertension. ${ }^{[18]}$

\section{CONCLUSION}

Based on the present study, we conclude that etomidate when compared to thiopentone sodium is a safe anaesthetic agent for electroconvulsive therapy with minimal side effects.

\section{REFERENCES}

[1] Kumar A, Sharma DK, Mani R. A comparison of propofol and thiopentone for electroconvulsive therapy. J Anaesthesiol Clin Pharmacol 2012;28(3):353-7.

[2] Abdollahi MH, Izadi A, Hajiesmaeili MR, et al. Effect of etomidate versus thiopental on major depressive disorder in electroconvulsive therapy, a randomized double-blind controlled clinical trial. J ECT 2012;28(1):10-3.

[3] Zahavi GS, Dannon P. Comparison of anesthetics in electroconvulsive therapy: an effective treatment with the use of propofol, etomidate, and thiopental. Neuropsychiatr Dis Treat 2014;10:383-9.

[4] Omprakash TM, Ali MI, Anand B, et al. Comparision of thiopentone sodium and propofol in ECT anaesthesia. Indian J Psychol Med 2008;30(1):48-51.

[5] Gabor G, Judit T, Zsolt I. Comparison of propofol and etomidate regarding impact on seizure threshold during electroconvulsive therapy in patients with schizophrenia. Neuropsychopharmacol Hung 2007;9(3):125-30.

[6] Graveland PE, Wierdsma AI, van den Broek WW, et al. A retrospective comparison of the effects of propofol and etomidate on stimulus variables and efficacy of electroconvulsive therapy in depressed inpatients. Prog Neuropsychopharmacol Biol Psychiatry 2013;45:230-5.

[7] Geretsegger C, Nickel M, Judendorfer B, et al. Propofol and methohexital as anesthetic agents for electroconvulsive therapy: a randomized, double-blind comparison of electroconvulsive therapy seizure quality, therapeutic efficacy, and cognitive performance. J ECT 2007;23(4):239-43.
[8] Martínez-Amoros E, Ortiz GV, Moli PM, et al. Propofol and thiopental as anesthetic agents in electroconvulsive therapy: a retrospective study in major depression. Rev Psiquiatr Salud Ment 2014;7(1):42-7.

[9] Manjula BP, Nagaraja PS. Comparison of thiopentone sodium and propofol as anesthetic agents for modified electroconvulsive therapy. Karnataka Anaesth J 2015;1(3):128-33.

[10] Hoyer C, Kranaster L, Janke C, et al. Impact of the anesthetic agents ketamine, etomidate, thiopental, and propofol on seizure parameters and seizure quality in electroconvulsive therapy: a retrospective study. Eur Arch Psychiatry Clin Neurosci 2014;264(3):255-61.

[11] Salehi B, Mohammadbeigi A, Kamali AR, et al. Impact comparison of ketamine and sodium thiopental on anesthesia during electroconvulsive therapy in major depression patients with drug-resistant; a doubleblind randomized clinical trial. Ann Card Anaesth 2015;18(4):486-90.

[12] Boey WK, Lai FO. Comparison of propofol and thiopentone as anaesthetic agents for electroconvulsive therapy. Anaesthesia 1990;45(8):623-8.

[13] Rosa MA, Rosa MO, Belegarde IM, et al. Recovery after ECT: comparison of propofol, etomidate and thiopental. Rev Bras Psiquiatr 2008;30(2):149-51.

[14] Canbek O, Ipekcioglu D, Menges 00, et al. Comparison of propofol, etomidate, and thiopental in anesthesia for electroconvulsive therapy: a randomized, double-blind clinical trial. J ECT 2015;31(2):91-7.

[15] Conca A, Germann R, Konig P. Etomidate vs. thiopentone in electroconvulsive therapy. An interdisciplinary challenge for anesthesiology and psychiatry. Pharmacopsychiatry 2003;36(3):94-7.

[16] Saffer S, Berk M. Anesthetic induction for ECT with etomidate is associated with longer seizure duration than thiopentone. J ECT 1998;14(2):89-93.

[17] Gazdag G, Kocsis N, Tolna J, et al. Etomidate versus propofol for electroconvulsive therapy in patients with schizophrenia. J ECT 2004;20(4):225-9.

[18] Swaim JC, Mansour M, Wydo SM, et al. A retrospective comparison of anesthetic agents in electroconvulsive therapy. J ECT 2006;22(4):243-6. 